\title{
Identification of a fibrinogen-related protein (FBN9) gene in neotropical anopheline mosquitoes
}

\author{
Sabrina B Oliveira', Izabela C Ibraim', Wanderli P Tadei ${ }^{2}$, Jeronimo C Ruiz ${ }^{3}$, Laila A Nahum ${ }^{3,4}$, Cristiana FA Brito',
} Luciano A Moreira ${ }^{1 *}$

\begin{abstract}
Background: Malaria has a devastating impact on worldwide public health in many tropical areas. Studies on vector immunity are important for the overall understanding of the parasite-vector interaction and for the design of novel strategies to control malaria. A member of the fibrinogen-related protein family, fbng, has been well studied in Anopheles gambiae and has been shown to be an important component of the mosquito immune system. However, little is known about this gene in neotropical anopheline species.
\end{abstract}

Methods: This article describes the identification and characterization of the fbn 9 gene partial sequences from four species of neotropical anopheline primary and secondary vectors: Anopheles darlingi, Anopheles nuneztovari, Anopheles aquasalis, and Anopheles albitarsis (namely Anopheles marajoara). Degenerate primers were designed based on comparative analysis of publicly available Aedes aegypti and An. gambiae gene sequences and used to clone putative homologs in the neotropical species. Sequence comparisons and Bayesian phylogenetic analyses were then performed to better understand the molecular diversity of this gene in evolutionary distant anopheline species, belonging to different subgenera.

Results: Comparisons of the fbng gene sequences of the neotropical anophelines and their homologs in the An. gambiae complex (Gambiae complex) showed high conservation at the nucleotide and amino acid levels, although some sites show significant differentiation (non-synonymous substitutions). Furthermore, phylogenetic analysis of fbng nucleotide sequences showed that neotropical anophelines and African mosquitoes form two well-supported clades, mirroring their separation into two different subgenera.

Conclusions: The present work adds new insights into the conserved role of fbng in insect immunity in a broader range of anopheline species and reinforces the possibility of manipulating mosquito immunity to design novel pathogen control strategies.

\section{Background}

Mosquito-borne diseases, including malaria and arboviruses, such as dengue, depend on complex interactions among pathogens, insect vectors, and hosts. Studies of vector immunity are of particular importance to understanding these complex interactions and could lead to the development of novel disease control strategies [1-6]. Vectorial competence, which refers to the ability of arthropods to acquire, maintain, and transmit microbial agents [7], is directly related to insect immunity. Several immunity-related genes have been identified in

\footnotetext{
* Correspondence: luciano@cpqrr.fiocruz.br

'Laboratório de Malária, Centro de Pesquisas René Rachou, Fundação

Oswaldo Cruz - FIOCRUZ, Belo Horizonte, MG 30190-002, Brazil

Full list of author information is available at the end of the article
}

Old World vectors [8-10]. However, related studies in neotropical anopheline species are still incipient.

Among the important immunity genes are the ones enconding members of the fibrinogen-related protein family (FREP or FBN), which are pattern recognition receptors and have been considered as promising candidates for parasite control strategies [10-12]. Within this family, the $f b n 9$ gene was found to be upregulated when Anopheles gambiae mosquitoes were fed on blood infected with parasites (Plasmodium falciparum) or bacteria (Escherichia coli or Staphylococcus aureus) [10]. Furthermore, when this gene was knocked-down, parasite loads significantly increased [10]. More recently, the $f b n 9$ gene was found to be conserved among members of the An. gambiae complex [13]. The An. gambiae

\section{Biomed Central}

() 2011 Oliveira et al; licensee BioMed Central Ltd. This is an Open Access article distributed under the terms of the Creative Commons Attribution License (http://creativecommons.org/licenses/by/2.0), which permits unrestricted use, distribution, and reproduction in any medium, provided the original work is properly cited. 
complex comprehends seven closely related species $(A n$. gambiae, Anopheles arabiensis, Anopheles melas, Anopheles merus, Anopheles bwambae, and Anopheles quadriannulatus A and B), from which An. gambiae and An. arabiensis have been described as important vectors of human malaria [14].

In South America, the most important malaria vectors comprise the Anopheles (Nyssorhynchus) darlingi, Anopheles albimanus, and members of the Anopheles albitarsis complex (An. albitarsis, Anopheles oryzalimnetes, Anopheles marajoara, Anopheles deaneorum, Anopheles janconnae, and $A n$. albitarsis F) [15]. Secondary vectors include Anopheles nuneztovari, Anopheles aquasalis and other members of the same subgenera [16-19]. In Brazil, of the 54 anopheline species that have been recorded, 13 were found to be naturally infected with Plasmodium spp. $[16,20]$, emphasizing the importance of further vector/ parasite studies, including laboratory-based infections.

The identification and characterization of the $f b n 9$ gene partial sequences from four species of neotropical anopheline mosquitoes has been performed in this study, followed by comparisons to sequences of the $A n$. gambiae complex available in public databases. Further comparisons of synonymous (silent) and non-synonymous (changing) substitution rates in its amino acid sequence have been applied to try understanding its molecular evolution. This study allowed a better understanding of the molecular diversity and predicted function of this immunity gene in a broader range of mosquito species.

\section{Methods}

Mosquito collection and identification

Mosquitoes were collected from different locations (6070 specimens from each locality; Table 1). Anopheles darlingi specimens were collected from larval breeding sites and by capturing adults through traps in rural areas of Manaus (Amazon, Brazil). Larvae were also collected and maintained in rearing conditions and adults identified upon emergence. Anopheles albitarsis samples were also collected in Porto Velho (Rondonia, Brazil). Anopheles aquasalis was obtained from a laboratory colony reared at $27^{\circ} \mathrm{C}, 80 \%$ humidity and $12 \mathrm{~h} \mathrm{L:D} \mathrm{cycle}$ maintained at FIOCRUZ, Belo Horizonte-MG, Brazil. Mosquitoes were individually identified according to their morphology through taxonomic keys, which are based on particularities on their tarsi, abdomen, and wing veins [21]. The identification of specimens of the An. albitarsis complex was confirmed by sequencing the internal transcribed spacer 2, ITS2, as described below.

\section{ITS2 genotyping}

Genomic DNA has been isolated from pools of 10 mosquitoes following previously published protocol [22].
PCR reactions were performed using the primers CP16 (5'-GCGGGTACCATGCTTAAATTTAGGGGGTA-3') and CP17 (5'-GCGCCGCGGTGTGAACTGCAGGACACATG-3') [23]. Each reaction contained $0.2 \mu \mathrm{M}$ of each primer, $0.2 \mathrm{mM}$ dNTPs, buffer $(50 \mathrm{mM} \mathrm{KCl}, 10 \mathrm{mM}$ Tris- $\mathrm{HCl} \mathrm{pH}$ 8.4. $1.5 \mathrm{mM} \mathrm{MgCl}_{2}, 1 \mathrm{mg} / \mathrm{mL}$ gelatin), milli-Q water to a final volume of $15 \mu \mathrm{L}$ and $20 \mathrm{ng}$ of genomic DNA. Samples were subjected to 25 cycles of $94^{\circ} \mathrm{C} 1 \mathrm{~min}, 50^{\circ} \mathrm{C} 2 \mathrm{~min}$, and $72^{\circ} \mathrm{C} 2 \mathrm{~min}$ and amplified products were visualized on agarose gels. PCR reactions were purified with the ExoSAP-IT ${ }^{\circledR}$ (USB), following the manufacturer protocol. PCR products were cloned into pGEM $^{\circledR}$ - T Easy vector system (Promega) and after colony screening, positive clones were sequenced for the ITS2 region. Sequencing reactions were performed using the DYEnamic ${ }^{\mathrm{TM}}$ ET Dye Terminator Cycle Sequencing Kit and a MegaBACE ${ }^{\mathrm{TM}}$ DNA analysis system (GE Healthcare Life Sciences).

Multiple sequences were obtained for each species (Table 1) depending on the PCR colony screening results and then further assembled. Sequences were analysed using PHRED/PHRAP/Consed [24] as well as by the Crossmatch software to trim vector sequences [25]. Sequence similarity searches were performed using the blastx program of the BLAST package against different databases [26]. Further comparisons have been performed between sequences described in the present work with those published elsewhere [23,27].

\section{Identification of $f b n 9$}

The identification of the $f b n 9$ gene sequences of four neotropical anophelines (Table 1) was performed through PCR and sequencing analyses as follows. First, degenerate primers were designed based upon highly similar regions between two fbn9 homologs in An. gambiae (AGAP011197) and Ae. aegypti (AY432284.1) translated sequences available in public databases. PCR reactions were performed with $0.5 \mu \mathrm{M}$ of each primer: 5fbn_deg4 (5'-AAYCARGCNCAYYTNGARAA-3') and 3fbn_deg4 (5'-CANCCICCICCRAAYTTNGTYTG-3') with the following parameters: $94^{\circ} \mathrm{C} 5 \mathrm{~min}, 15$ cycles $\left(94^{\circ} \mathrm{C} 30 \mathrm{sec}, 50^{\circ} \mathrm{C} 30 \mathrm{sec}, 72^{\circ} \mathrm{C} 1 \mathrm{~min}\right)$ where the annealing temperature was reduced by $1^{\circ} \mathrm{C}$ per cycle; followed by 20 cycles $\left(94^{\circ} \mathrm{C} 30 \mathrm{sec}, 50^{\circ} \mathrm{C} 30 \mathrm{sec} 72^{\circ} \mathrm{C} 60\right.$ sec). Part of the amplified product was checked on agarose gel. In the absence of unspecific amplified bands, PCR products were re-amplified.

Fragments from the positive PCR reactions were purified using the QIAEX II ${ }^{\circledR}$ Gel Extraction Kit (Qiagen) and cloned into pGEM ${ }^{\circledR}-\mathrm{T}$ Easy vector system (Promega). Bacterial clones (E. coli - TOP10) were checked by PCR using the T7 (5'-TAATACGACTCACTATAGGG-3') and SP6 (5'-ATTTAGGTGACACTAG-3') primers $\left(94^{\circ} \mathrm{C} 2 \mathrm{~min}, 35\right.$ cycles of $94^{\circ} \mathrm{C} 30 \mathrm{sec}, 45^{\circ} \mathrm{C}$ 
Table 1 Sequences used for the FBN9 phylogenetic analysis

\begin{tabular}{|c|c|c|c|c|}
\hline Accession Number & $\mathrm{Gi}$ & Sequence & Species & Origin \\
\hline HQ188296 & 312145129 & Contig2-fbn-aqua & An. aquasalis & Brazil (insectary, CPqRR) \\
\hline HQ188298 & 312145133 & Contig3-fbn-aqua & An. aquasalis & Brazil (insectary, CPqRR) \\
\hline HQ188295 & 312145127 & Contig21-fbn-darl & An. darlingi & Brazil (Manaus, AMª) \\
\hline HQ188300 & 312145137 & Contig7-fbn-darl & An. darlingi & Brazil (Manaus,AM) \\
\hline HQ188297 & 312145131 & Contig2-fbn-albit & An. marajoara & Brazil (Manaus, AM) \\
\hline HM623677 & 312145141 & Contig14-fbn-albit & An. marajoara & Brazil (Manaus, AM) \\
\hline HM635775 & 312145143 & Contig1-fbn-albit & An. marajoara & Brazil (Manaus, AM) \\
\hline HQ188299 & 312145135 & Contig5-fbn-albit.ro & An. marajoara & Brazil (Porto Velho, RO) \\
\hline HQ188294 & 312145125 & Contig19-fbn-nunezv2 & An. nuneztovari & Brazil (Manaus, AM) \\
\hline HQ188301 & 312145139 & Contig8-fbn- nunezv & An. nuneztovari & Brazil (Manaus, AM) \\
\hline EU304626.1 & 167861637 & ARA087_B & An. arabiensis & Cameroon (Kousseri) \\
\hline EU304631.1 & 167861647 & ARA125_A & An. arabiensis & Cameroon (Kousseri) \\
\hline EU304652.1 & 167861689 & GAM72_A & An. gambiae & Cameroon (Mbebé and Nyabéssan) \\
\hline EU304650.1 & 167861685 & GAM69_A & An. gambiae & Cameroon (Mbebé and Nyabéssan) \\
\hline EU304649.1 & 167861683 & GAM66 & An. gambiae & Cameroon (Mbebé and Nyabéssan) \\
\hline EU304647.1 & 167861679 & GAM15_A & An. gambiae & Cameroon (Mbebé and Nyabéssan) \\
\hline EU304646.1 & 167861677 & GAM13_B & An. gambiae & Cameroon (Mbebé and Nyabéssan) \\
\hline EU304644.1 & 167861673 & GAM07_B & An. gambiae & Cameroon (Mbebé and Nyabéssan) \\
\hline EU304682.1 & 167861749 & QUA24_B & An. quadriannulatus & South Africa (Kruger National Park) \\
\hline EU304675.1 & 167861735 & QUA16 & An. quadriannulatus & South Africa (Kruger National Park) \\
\hline EU304670.1 & 167861721 & MER563_A & An. merus & Mozambique (Furvela) \\
\hline EU304668.1 & 167861721 & MER562_A & An. merus & Mozambique (Furvela) \\
\hline EU304658.1 & 167861701 & MEL22 & An. melas & Cameroon (Ipono) \\
\hline EU304656.1 & 167861697 & MEL15 & An. melas & Cameroon (Ipono) \\
\hline EU304639.1 & 167861663 & BWA17 & An. bwambae & Uganda (Bwamba) \\
\hline EU304641.1 & 167861667 & BWA18_B & An. bwambae & Uganda (Bwamba) \\
\hline
\end{tabular}

${ }^{\mathrm{a} A M}$ - Amazon State, RO - Rondonia State, Brazil.

$30 \mathrm{sec}$ and $72^{\circ} \mathrm{C} 60 \mathrm{sec}$; followed by $5 \mathrm{~min}$ at $72^{\circ} \mathrm{C}$ ). PCR products were sequenced as described above using $\mathrm{T} 7$ and SP6 primers. High quality consensus sequences were subjected to sequence similarity searches using the blastx program against an An. gambiae protein database built in the present work. The top BLAST hits to the An. gambiae fbn9 gene sequence (GenBank Gi: 167861677) were considered as potential orthologs for further analysis.

\section{Sequence analysis}

All $f b n 9$ gene sequences obtained from An. aquasalis, An. darlingi, An. albitarsis, and An. nuneztovari were aligned with ClustalX [28] and manually adjusted with BioEdit [29]. Analyses of the alignment coverage, the presence of conserved domains, the number of singlenucleotide polymorphisms (SNPs), the percentages of synonymous and non-synonymous substitutions, and the rates of transitions and transversions among the nucleotide sequences were performed through MEGA software [30].

For the studies on selection pressure, another multiple sequence alignment was built including other additional
$60 \mathrm{fbn} 9$ sequences from the An. gambiae complex deposited at the GenBank and described elsewhere [13]. Analysis of the alignments in terms of dN, dS, and dN/ dS ratio were again performed with MEGA. To calculate the frequency of synonymous and non-synonymous substitutions, we applied the Nei-Gojobori method with the Jukes-Cantor correction [31,32].

\section{Phylogenetic analysis}

For the phylogenetic analysis, a total of $21 f b n 9$ nucleotide sequences from 10 species have been selected that include: four partial sequences from $A n$. darlingi, $A n$. aquasalis, An. nuneztovari, and An. albitarsis (Amazon and Rondonia, Brazil) obtained in the present work together with other 16 sequences from six species belonging to the An. gambiae complex (Table 1). Multiple sequences from the same species, identified as $\mathrm{A}$ and $\mathrm{B}$, refer to different alleles of the same specimen or different specimens collected.

The use of nucleotide sequences was chosen due to the high level of conservation observed in the amino acid sequences found in our species, which would result in less informative output. Both 5' and 3' ends from the 
An. gambiae sequences, which were not present in our sequences, were removed from the final alignment. The final alignment contained 365 sites, which corresponds to $42.9 \%$ of the $A n$. gambiae fbn9 gene sequence.

Bayesian analysis with the Markov chain Monte Carlo (MCMC) sampling method as implemented in MrBayes (version 3.1) [33] has been performed. MCMC analyses were run as four chains ( 1 cold and 3 heated chains) for $1,500,000$ generations, with sampling occurring every 1000 generations and with $25 \%$ of the initial samples discarded as "burn-in". The General Time Reversible (GTR) model assuming a gamma distribution with variation rate between the sites and an invariable proportion of the sites (GTR + inv + gamma) has been adopted. The sequence of $A n$. nuneztovari was used as outgroup to construct the phylogenetic tree. Support values of the recovered trees were estimated as Bayesian posterior probabilities (pp). Well-supported clusters with the posterior probability of at least 0.80 were considered for data interpretation. The consensus tree was visualized and edited in FigTree, version 1.2 [34].

\section{Results}

In the present study, partial nucleotide sequences of an important immune-related gene $(f b n 9)$ from four neotropical anopheline mosquito species have been obtained. Sequencing of the ITS2 region of the neotropical mosquito specimens allowed the identification of species with higher accuracy in addition to morphological identification [21]. Further comparisons of sequences from neotropical anophelines with publicly available sequences from the An. gambiae complex have been performed to apply selection pressure studies and phylogenetic analysis.

\section{Gene cloning and sequencing}

The $f b n 9$ gene was identified through PCR in An. aquasalis, An. darlingi, An. marajoara, and An. nuneztovari mosquitoes (Figure 1). Results were confirmed through DNA sequencing followed by similarity searches using blastx. All sequences matching FBN9 protein sequences as the top hit with significant E-values and high percentage of identity (See additional file 1: Table S1). Sequences had around 360 nucleotides, corresponding to $42.5 \%$ of the gene, from positions 84 to 444 of the sequence (Gi: 167861677).

For An. aquasalis, a higher molecular weight band was detected (Figure 1) and sequenced, but no significant sequence similarity was detected through BLAST searches.

\section{Sequence analysis}

The analysis of the sequences obtained for the neotropical mosquito species showed 79 SNPs in 360 nucleotides,

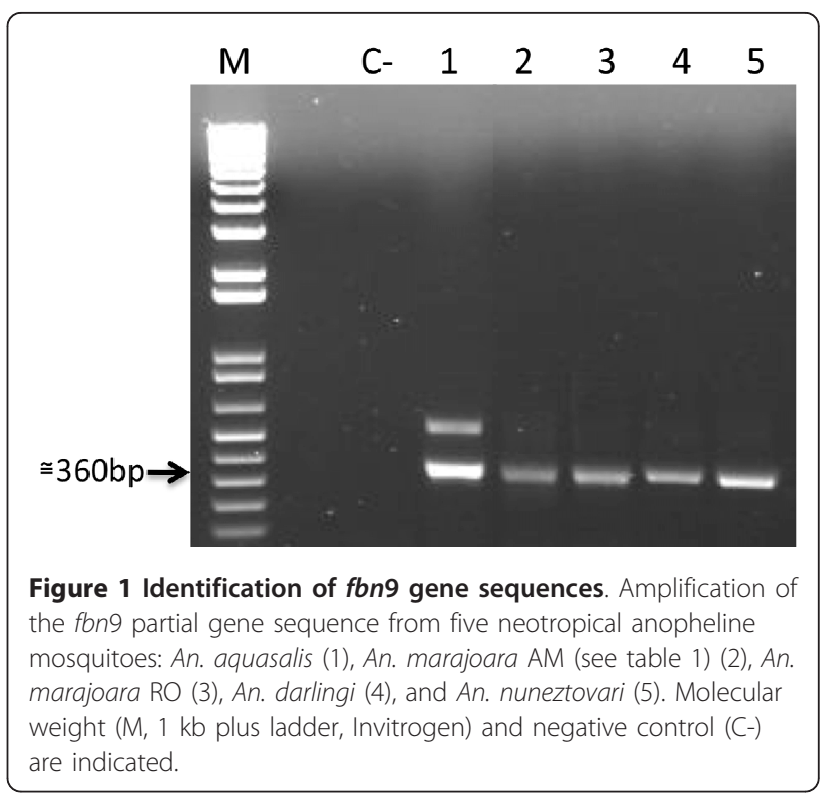

where $11.33 \%$ correspond to the first, $7.59 \%$ to the second, and $81.01 \%$ to the third codon positions. Of the 72 polymorphic codons, 64 correspond to synonymous substitutions and eight are non-synonymous. In total, 61 transitions and 25 transversions were detected. When the $A n$. gambiae complex sequences were included in the analysis, 128 nucleotide polymorphisms and 104 polymorphic codons were observed, resulting in 75 synonymous and 29 non-synonymous substitutions. A high degree of conservation among the amino acid sequences from anopheline mosquitoes has been found (Figure 2).

\section{Phylogenetic analysis}

Phylogenetic relationships among 21 partial $f b n 9$ gene sequences from 10 distinct anopheline species (Table 1) were reconstructed using a Bayesian approach as described above (Methods). The tree topology (Figure 3) suggests the presence of two well-supported sequence groups ( $\mathrm{pp}=1$ ) corresponding to the African (black) and Neotropical (green) species analyzed in the present study. The former group includes different lineages of five species of the Gambiae complex with two lineages of $A n$. merus (MER562_A and MER563_A) clustered together with other two of An. quadriannulatus (QUA16 and QUA24-B). Other relationships in the African group are also well-resolved considering the posterior probability cutoff (at least 0.80) adopted in our approach.

The phylogenetic relationships among the five neotropical species (green) are strongly supported by the analysis as showed in Figure 3. The two sequences of $A n$. albitarsis (An. marajoara) originated from Amazon and Rondonia, Brazil, are closely related $(\mathrm{pp}=1)$ and form a 


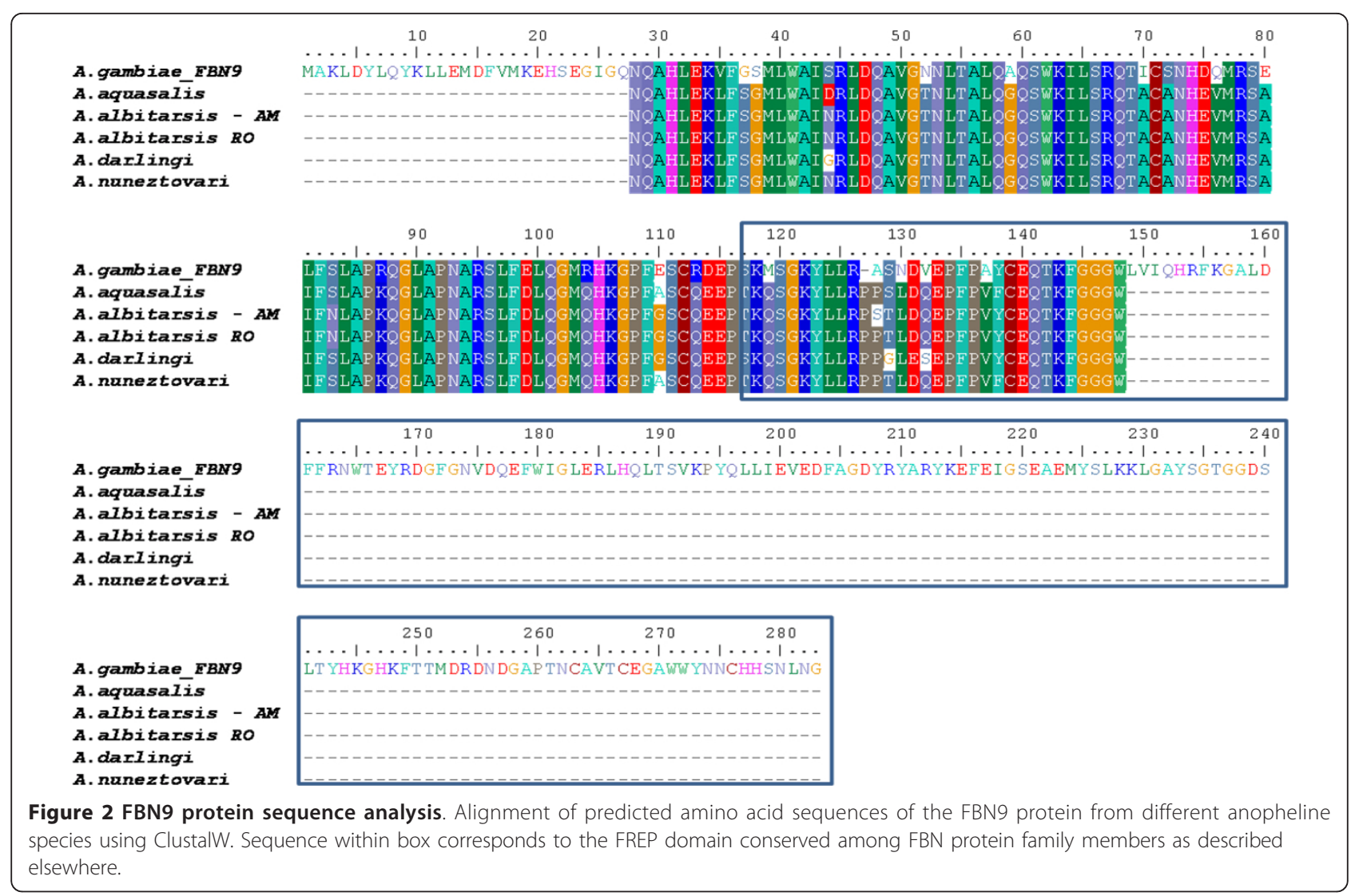

sister group with sequences of $A n$. aquasalis and $A n$. nuneztovari ( $\mathrm{pp}=0.98)$. The An. darlingi sequence seems to be more divergent across the Neotropical species. Further phylogenetic analysis supported the orthology prediction performed through sequence similaritybased searches aforementioned.

\section{Discussion}

The unavailability of genomes from neotropical anopheline species hamper most of the studies related to function and evolutionary aspects of important genes in mosquitoes, which makes the use of alternative techniques the only available solution to overcome this problem. Recently, studies on differential gene expression of the coastal malaria vector An. aquasalis, infected with Plasmodium vivax, have been performed and three fibrinogen-related genes have been found, which differ from fbn9 [35].

In An. gambiae, FBN9 has been known to have an important function on the mosquito immune system, acting as a pattern recognition receptor. Its expression is up-regulated when mosquitoes are infected with bacteria and Plasmodium species [11]. The participation of this protein on the mosquito's interaction with parasites is very important because it determines the insect's vectorial competence [36].
This study showed the high conservation pattern present in this protein in both An. gambiae and in neotropical species belonging to the subgenus Nyssorhynchus, suggesting that this protein might have the same function in all these species. As recently stated, fibrinogen related proteins (FREPs), where FBN9 belongs, are part of the basal immune surveillance of mosquitoes by interacting with mosquito bacterial flora [11]. This may explain this conservation as all mosquito species ubiquitously harbour bacteria.

A comparison of synonymous and nonsynonymous substitution rates in protein coding genes provides an important means for understanding molecular evolution [37]. When comparing the sequences in different Anopheline species, a higher frequency of polymorphic sites on the third base of the codon reflects the higher presence of synonymous substitutions. The results presented here are in concordance with previous work analyzing the patterns of molecular evolution in the $f b n 9$ gene using 60 sequences of six species from the Gambiae complex [13]. Here, synonymous substitutions are in higher frequency than non-synonymous substitutions resulting in a $d N / d S<1$ ratio, which corresponds to a negative or purifying natural selective pressure, perhaps limiting alterations at protein level. This observation suggests that this region may be important to 


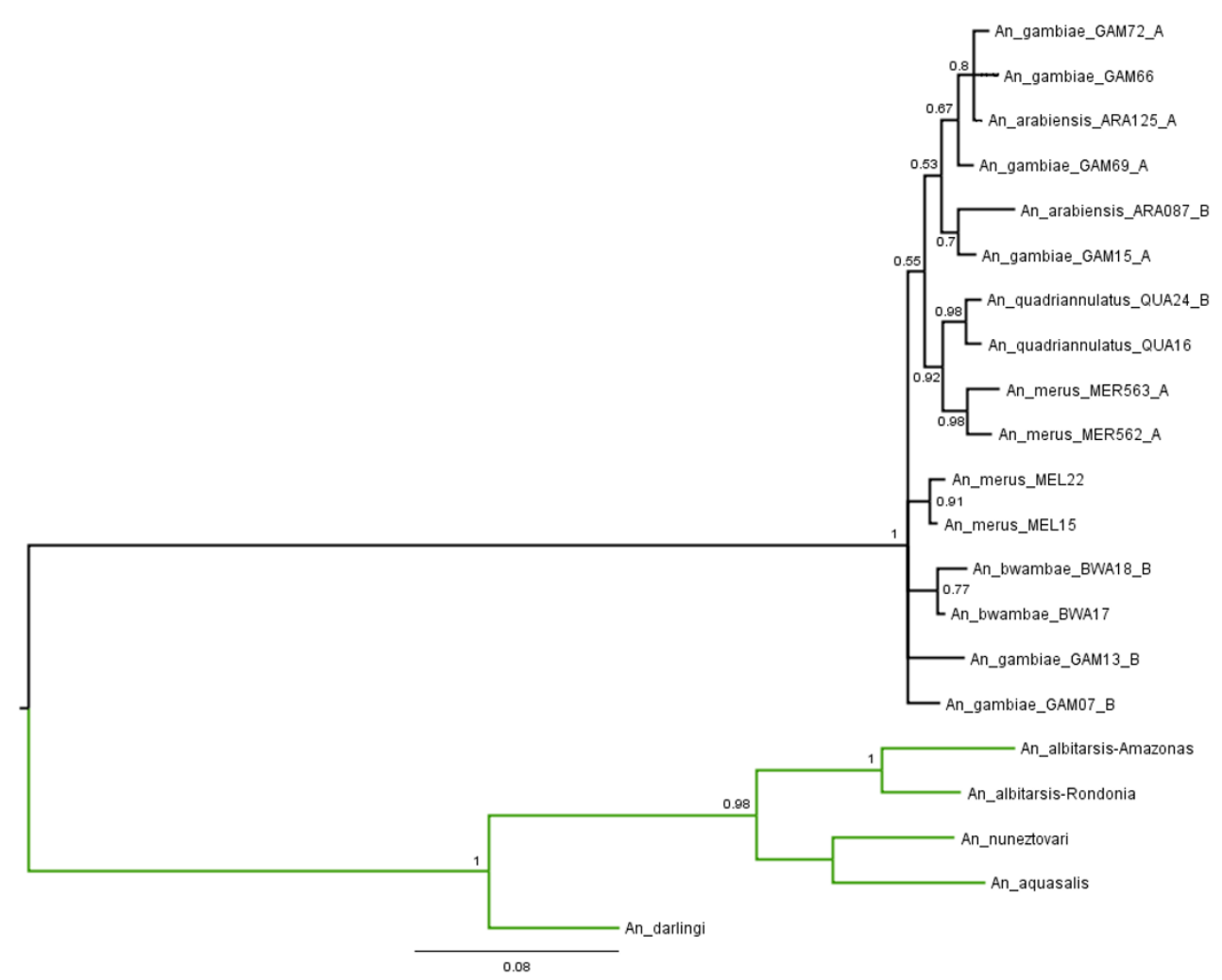

Figure 3 Phylogenetic tree with 21 partial sequences of the $f b n 9$ gene from 10 anopheline species (Table 1). Branches leading to the Brazilian (present study) and African anopheline species are indicated in green and black, respectively. Posterior probability values (pp) are indicated in this 50\% majority-rule consensus (unrooted) tree. Letters A and B following the specimen abbreviation indicate two alleles of a single individual specimen as described elsewhere [13].

maintaining the function and/or the structure of this protein. Recently, Lehmann and colleagues studied four immunity-related genes (SP14D1, GNBP, defensin, and gambicin) in An. gambiae and found no evidence to prove that selection was mediated by pathogens that are transmitted to humans [38].

The indication of conserved function of the $f b n 9$ gene between the Gambiae complex and the Brazilian anophelines is interesting if one considers that the separation of sub-genus Cellia and Nyssorhynchus occurred around 94 my ago, based on mtDNA analysis [39]. Further studies on the expression of $f b n 9$ in Neotropical mosquito species and its role during infection with Plasmodium species will provide further information on this important immune-related gene.

\section{Conclusions}

In the present work, the $f b n 9$ gene sequences of four neotropical anopheline species have been compared with their homologs in the An. gambiae complex to gain insights into insect immunity. Sequence analysis shows a high degree of conservation of the $f b n 9$ gene in all species compared and suggests that these sequences are under negative selection pressure. Bayesian phylogenetic analysis supports the hypothesis of neotropical anophelines (subgenus Nyssorhynchus) and African mosquitoes (subgenus Cellia) forming two well-supported clades. The present work suggests a possible conserved role for $f b n 9$ in the immune response of a broader range of anopheline species. Identification of the genes involved in the mosquito immune response to parasite infections shall allow the design of novel pathogen control strategies.

\section{Additional material}

Additional file 1: Blast analysis of the FBN9 translated sequences. Blastx analysis of the FBN9 translated sequences against the top hit from A. gambiae protein database (FBN9 - Gi: 167861677)

\section{Abbreviations}

MCMC: Markov chain Monte Carlo; NCBI: National Center for Biotechnology Information; PCR: Polymerase Chain Reaction. PCR primer abbreviation: 5fbn_deg4: Forward fbn degenerated primer 4; 3fbn_deg4: Reverse fbn degenerated primer 4; CP16: Forward rDNA ITS2 region primer; CP17: Reverse rDNA ITS2 region primer; T7: T7 universal primer; SP6: SP6 universal primer. 


\section{Acknowledgements}

This work was funded by FAPEMIG, INCT-EM, and FIOCRUZ. LAN was funded by the $\mathrm{NIH} /$ Fogarty International Center (Grants: D43TW007012 and 2D43TW007012). LAM and CFAB are fellow researchers from CNPq. We thank the support from PDTIS-CPaRR sequencing facility. We are grateful to Fernanda Rezende for technical assistance and Francesca D. Frentiu for critical reading of the manuscript. We are in debt to Dr. Roberto S. Rocha (FIOCRUZ-AM) for providing logistics during mosquito collection.

\section{Author details}

'Laboratório de Malária, Centro de Pesquisas René Rachou, Fundação Oswaldo Cruz - FIOCRUZ, Belo Horizonte, MG 30190-002, Brazil. 'Laboratório de Malária e Dengue, Instituto Nacional de Pesquisas da Amazônia - INPA, Manaus, AM 69060-000, Brazil. ${ }^{3}$ Laboratório de Parasitologia Celular e Molecular, Centro de Pesquisas René Rachou, Fundação Oswaldo Cruz FIOCRUZ, Belo Horizonte, MG 30190-002, Brazil. ${ }^{4}$ Centro de Excelência em Bioinformática, Fundação Oswaldo Cruz - FIOCRUZ, Belo Horizonte, MG 30190-110, Brazil.

\section{Authors' contributions}

SBO participated in the study design and carried out the experiments. ICI helped on the cloning and sequencing. WPT collected and identified mosquito specimens. JCR helped on sequences analysis. LAN designed and coordinated the phylogenetic analysis and co-wrote this manuscript. CFAB helped in the study design and in all experimental phases. LAM conceived and coordinated the study and drafted the manuscript. All authors read and approved the final manuscript.

\section{Competing interests}

The authors declare that they have no competing interests.

Received: 13 September 2010 Accepted: 2 February 2011

Published: 2 February 2011

\section{References}

1. Blandin S, Levashina EA: Mosquito immune responses against malaria parasites. Curr Opin Immunol 2004, 16:16-20.

2. Chen $Y$, Weng $Z H$, Zheng LB: Innate immunity against malaria parasites in Anopheles gambiae. Insect Science 2008, 15:45-52.

3. Christophides GK, Zdobnov E, Barillas-Mury C, Birney E, Blandin S, Blass C, Brey PT, Collins FH, Danielli A, Dimopoulos G, Hetru C, Hoa NT, Hoffmann JA, Kanzok SM, Letunic I, Levashina EA, Loukeris TG, Lycett G, Meister S, Michel K, Moita LF, Müller HM, Osta MA, Paskewitz SM, Reichhart JM, Rzhetsky A, Troxler L, Vernick KD, Vlachou D, Volz J, von Mering C, Xu J, Zheng L, Bork P, Kafatos FC: Immunity-related genes and gene families in Anopheles gambiae. Science 2002, 298:159-165.

4. Dimopoulos G, Muller HM, Levashina EA, Kafatos FC: Innate immune defense against malaria infection in the mosquito. Curr Opin Immunol 2001, 13:79-88.

5. Levashina EA: Immune responses in Anopheles gambiae. Insect Biochem Mol Biol 2004, 34:673-678.

6. Michel K, Kafatos FC: Mosquito immunity against Plasmodium. Insect Biochem Mol Biol 2005, 35:677-689.

7. Goddard J: Infectious Diseases and Arthropods. 2 edition. Starkville and Jackson: Humana Press; 2008.

8. Brennan JD, Kent M, Dhar R, Fujioka H, Kumar N: Anopheles gambiae salivary gland proteins as putative targets for blocking transmission of malaria parasites. Proc Natl Acad Sci USA 2000, 97:13859-13864.

9. Osta MA, Christophides GK, Kafatos FC: Effects of mosquito genes on Plasmodium development. Science 2004, 303:2030-2032.

10. Dong Y, Aguilar R, Xi Z, Warr E, Mongin E, Dimopoulos G: Anopheles gambiae immune responses to human and rodent Plasmodium parasite species. PLoS Pathog 2006, 2:e52.

11. Dong Y, Dimopoulos G: Anopheles fibrinogen-related proteins provide expanded pattern recognition capacity against bacteria and malaria parasites. J Biol Chem 2009, 284:9835-9844.

12. Hoffmann JA, Reichhart JM: Drosophila innate immunity: an evolutionary perspective. Nat Immunol 2002, 3:121-126.

13. Parmakelis A, Slotman MA, Marshall JC, Awono-Ambene PH, AntonioNkondjio C, Simard F, Caccone A, Powell JR: The molecular evolution of four anti-malarial immune genes in the Anopheles gambiae species complex. BMC Evol Biol 2008, 8.

14. Coluzzi M, Sabatini A, della Torre A, Di Deco MA, Petrarca V: A polytene chromosome analysis of the Anopheles gambiae species complex. Science 2002, 298:1415-1418.

15. Motoki MT, Wilkerson RC, Sallum MA: The Anopheles albitarsis complex with the recognition of Anopheles oryzalimnetes Wilkerson and Motoki, n. sp. and Anopheles janconnae Wilkerson and Sallum, n. sp. (Diptera: Culicidae). Mem Inst Oswaldo Cruz 2009, 104:823-850.

16. da Rocha JAM, de Oliveira SB, Povoa MM, Moreira LA, Krettli AU: Malaria vectors in areas of Plasmodium falciparum epidemic transmission in the Amazon region, Brazil. Am J Trop Med Hyg 2008, 78:872-877.

17. Tadei WP, Thatcher BD, Santos JMH, Scarpassa VM, Rodrigues IB, Rafael MS: Ecologic observations on anopheline vectors of malaria in the Brazilian Amazon. Am J Trop Med Hyg 1998, 59:325-335.

18. Zimmerman RH: Ecology of malaria vectors in the America and futuredirection. Mem Inst Oswaldo Cruz 1992, 87:371-383.

19. Tadei WP, Thatcher BD: Malaria vectors in the Brazilian amazon: Anopheles of the subgenus Nyssorhynchus. Rev Inst Med Trop Sao Paulo 2000, 42:87-94.

20. Deane LM: Malaria vectors in Brazil. Mem Inst Oswaldo Cruz 1986, 81:5-14.

21. Consoli RAGB, Oliveira RL: Principais mosquitos de importância sanitária no Brasil Rio de Janeiro: Editora FIOCRUZ; 1994

22. Rodrigues FG, Santos MN, de Carvalho TX, Rocha BC, Riehle MA, Pimenta PF, Abraham EG, Jacobs-Lorena M, Alves de Brito CF, Moreira LA: Expression of a mutated phospholipase A2 in transgenic Aedes fluviatilis mosquitoes impacts Plasmodium gallinaceum development. Insect Mol Biol 2008, 17:175-183.

23. Marrelli MT, Floeter-Winter LM, Malafronte RS, Tadei WP, Lourenco-deOliveira R, Flores-Mendoza C, Marinotti O: Amazonian malaria vector anopheline relationships interpreted from ITS2 rDNA sequences. Med Vet Entomol 2005, 19:208-218.

24. de la Bastide M, McCombie WR: Assembling genomic DNA sequences with PHRAP. Curr Protoc Bioinformatics 2007, 11, Unit11.4.

25. Phrap Homepage: phred, phrap, consed, swat, cross match and RepeatMasker Documentation. [http://www.phrap.org].

26. Altschul SF, Madden TL, Schaffer AA, Zhang J, Zhang Z, Miller W, Lipman DJ: Gapped BLAST and PSI-BLAST: a new generation of protein database search programs. Nucleic Acids Res 1997, 25:3389-3402.

27. Li C, Wilkerson R: Intragenomic ITS2 variation and its impact on PCR identification of an Anopheles malaria vector group. Am J Trop Med Hyg 2005, 73:297-297.

28. Thompson JD, Gibson TJ, Plewniak F, Jeanmougin F, Higgins DG: The CLUSTAL_X windows interface: flexible strategies for multiple sequence alignment aided by quality analysis tools. Nucleic Acids Research 1997, 25:4876-4882.

29. Hall TA: BioEdit: a user-friendly biological sequence alignment editor and analysis program for Windows 95/98/NT. Nucleic Acids Symp 1999, 41:95-98.

30. Tamura K, Dudley J, Nei M, Kumar S: MEGA4: Molecular evolutionary genetics analysis (MEGA) software version 4.0. Mol Biol Evol 2007, 24:1596-1599.

31. Nei $\mathrm{M}$, Gojobori T: Simple methods for estimating the numbers of synonymous and nonsynonymous nucleotide substitutions. Mol Biol Evol 1986, 3:418-426.

32. Jukes TH, Cantor CR, Munro HN: Evolution of Protein Molecules Academy Press; 1969.

33. Ronquist F, Huelsenbeck JP: MrBayes 3: Bayesian phylogenetic inference under mixed models. Bioinformatics 2003, 19:1572-1574.

34. Rambaut A: Tree Figure Drawing Tool, Version 1.3.1 Institute of Evolutionary Biology, University of Edinburgh; 2009.

35. Bahia AC, Kubota MS, Tempone AJ, Pinheiro WD, Tadei WP, Secundino NF, Traub-Cseko YM, Pimenta PF: Anopheles aquasalis Infected by Plasmodium vivax displays unique gene expression profiles when compared to other malaria vectors and plasmodia. PLoS One 2010, 5:e9795.

36. Kambris Z, Cook PE, Phuc HK, Sinkins SP: Immune activation by lifeshortening Wolbachia and reduced filarial competence in mosquitoes. Science 2009, 326:134-136.

37. Farfan M, Minana-Galbis D, Fuste MC, Loren JG: Divergent evolution and purifying selection of the flaA gene sequences in Aeromonas. Biol Direct 2009, 4:23. 
38. Lehmann T, Hume JC, Licht M, Burns CS, Wollenberg K, Simard F, Ribeiro JM: Molecular evolution of immune genes in the malaria mosquito Anopheles gambiae. PLoS One 2009, 4:e4549.

39. Moreno M, Marinotti O, Krzywinski J, Tadei WP, James AA, Achee NL, Conn JE: Complete mtDNA genomes of Anopheles darlingi and an approach to anopheline divergence time. Malar J 2010, 9:127.

doi:10.1186/1475-2875-10-21

Cite this article as: Oliveira et al:: Identification of a fibrinogen-related protein (FBN9) gene in neotropical anopheline mosquitoes. Malaria Journal 2011 10:21.

Submit your next manuscript to BioMed Central and take full advantage of:

- Convenient online submission

- Thorough peer review

- No space constraints or color figure charges

- Immediate publication on acceptance

- Inclusion in PubMed, CAS, Scopus and Google Scholar

- Research which is freely available for redistribution 